subject to suitable ethical controls. Days in hospital or numbers of admissions within the last 3 months of life, deaths within 2 days of admission from home, or within 7 days of admission from a care home have all been advocated as measures of quality of end-of-life care.

One alternative approach is to obtain the views of patients close to the end of life by means of interviews or questionnaires, but such studies encounter difficulties of identification, recruitment and attrition ${ }^{15}$ and are probably not practical outside academic research studies. A more fruitful approach for routine NHS use may be to seek the views of informal carers after death by interview or questionnaire. Such studies are also affected by identification and recruitment difficulties, and only obtain the retrospective views of proxies who are affected by the passage of time and grief. ${ }^{16}$

While no approach to measurement of the quality of end-of-life care is without its drawbacks, we advocate that an attempt be made to measure systematically the care provided in all settings in order to assess progress in improving end-of-life care for all. Each day in the UK 1500 people die. An annual postal survey of the next of kin of all people who died on a particular day 6 months previously could provide invaluable data.

Service initiatives on their own are unlikely to alter place of death greatly, since the factors influencing place of death are many and varied, and include powerful social and cultural factors. ${ }^{17}$ The real challenge therefore is to improve the quality of end-of-life care in all settings, wherever people spend their last weeks and days, and especially in the general wards of our hospitals which are increasingly the predominant place of death. Almost all health and social care professionals are to some extent involved in end-of-life care. This is predominantly a task for generalists, supported where appropriate by palliative care specialists. Death affects us all, both directly and indirectly: these are challenges to which we must rise.

\section{Stephen Barclay,}

Macmillan Postdoctoral Research Fellow,

General Practice Research Unit, Department of Public Health and Primary Care, University of Cambridge, Cambridge

\section{Antony Arthur,}

Senior Research Fellow, Sue Ryder Centre for Palliative and End of Life Studies, University of Nottingham, Nottingham

\section{REFERENCES}

1. Department of Health. Building on the best: end of life care initiative. London: Department of Health, 2004.

2. Townsend J, Frank A, Fermont D, et al. Terminal cancer care and patients' preference for place of death: a prospective study. BMJ 1990; 301(6749): 415-417.

3. Gott M, Seymour J, Bellamy G, et al. Older people's views about home as a place of care at the end of life. Palliat Med 2004; 18(5): 460-467.

4. Hinton J. Which patients with terminal cancer are admitted from home care? Palliat Med 1994; 8(3): 197-210.

5. Higginson I. Priorities and preferences for end of life care in England, Wales and Scotland. London: National Council for Palliative Care, 2003.

6. Thomas C, Morris S, Clark D. Place of death: preferences among cancer patients and their carers. Soc Sci Med 2004; 58(12): 2431-2444.

7. House of Commons Health Select Committee. Palliative care: Fourth report of session 2003-04. London: The Stationery Office, 2004

8. Higginson I, Sen-Gupta G. Place of care in advanced cancer: a qualitative systematic literature review of patient preferences. J Palliat Med 2000; 3(2): 287-300.

9. Parkes CM. Home or hospital? Terminal care as seen by surviving spouses. J R Coll Gen Pract 1978; 28(186): 19-30.

10. Burt J, Barclay S, Marshall N, et al. Continuity within primary palliative care: an audit of general practice outof-hours co-operatives. J Public Health 2004; 26(3): 275-276.

11. Thomas K. The Gold Standards Framework in community palliative care. Eur J Palliat Care 2006; 10(3) $113-115$.

12. Ellershaw J, Ward C. Care of the dying patient: the last hours or days of life. BMJ 2003; 326(7379): 30-34.

13. Pemberton C, Storey L, Howard A. The preferred place of care document: an opportunity for communication. Int J Palliat Nurs 2003; 9(10): 439-441.

14. Kendall M, Harris F, Boyd K, et al. Key challenges and ways forward in researching the 'good death': qualitative in-depth interview and focus group study. BMJ 2007; 334(7592): 521-524.

15. Ewing G, Rogers M, Barclay S, et al. Recruiting patients into a primary care based study of palliative care: why is it so difficult? Palliat Med 2004; 18(5): 452-459.

16. McPherson C, Addington-Hall J. Judging the quality of care at the end of life: can proxies provide reliable information? Soc Sci Med 2003; 56(1): 95-109.

17. Gomes B, Higginson I. Factors influencing death at home in terminally ill patients with cancer: systematic review. BMJ 2006; 332(7540): 515-518.

DOI: 10.3399/bjgp08X279724

ADDRESS FOR CORRESPONDENCE:

Stephen Barclay,

General Practice Research Unit,

Department of Public Health and Primary

Care, University of Cambridge, Cambridge.

E-mail: sigb2@medschl.cam.ac.uk

\title{
Collaboration in primary care: the need to see the bigger picture
}

The mantras of collaboration, teamwork, interdisciplinary learning, and education have been urged on primary healthcare teams for a very long time. In the UK, Spencer ${ }^{1}$ suggests that this advocacy goes back to the Dawson Report of $1920,{ }^{2}$ but observes:

'Nevertheless, although the PHCT [primary healthcare team] is widely advocated as the best means for delivering health care in the community, there are problems in realising this ambition."

Two papers in this issue illustrate the continuing nature of these teamwork problems ${ }^{3,4}$ The papers are concerned with the delivery of palliative care services, but the issues they expose are those associated with interdisciplinary teamwork rather than being uniquely related to palliative care.

It is accepted that to provide high quality preventive, curative, or rehabilitation care necessitates input from a range of healthcare and other practitioners. To 
provide such care requires effective communication between all contributors to the care of the individual or community. The basis for effective overall communication starts from good communication within a profession. Effective communication then needs to extend to members of other professions and disciplines who form the immediate working team and, subsequently, to members of other teams or organisations.

Communication is fundamental to effective teamworking. Focusing on primary care, we know that teamwork can be enhanced by: co-location; facilitated practice-based education; interprofessional learning; shared record systems; shared goals, plans, and activities; and possibly through shared management systems and remuneration. ${ }^{5-10}$

Fundamental to these approaches to the development of teamwork in primary health care is the idea that education, the organisation of services, and access to resources all need to be utilised to help facilitate and stimulate teamworking. Various approaches to education of practitioners in primary care have been used to develop teamwork. Thomas and colleagues in Liverpool in the 1980s and 1990s evaluated the impact of a facilitation team that included a district nurse, practice manager, and a GP. The team members worked with practices on topics and activities that were of interest to the practice team; for example, the development of stop smoking services and better quality services for people with leg ulcers. These were important activities and outcomes but:

\section{'... their most important effect was to help health workers to see how the contribution of others could enhance their own work. This resulted in an altered perception of others, and a changed expectation about working with others. ${ }^{6}$}

The Liverpool and Teamcare Valleys ${ }^{10}$ projects used multifaceted approaches to engage practitioners in change activities that were relevant and important to them, achieving development of teamworking through this shared activity. This approach is based on adult learning theory that recognises that adults will be engaged in education when it addresses practical concerns. However, as Craddock et $a /^{5}$ and Thomas $^{9}$ argue, the application of adult learning theory alone is not sufficient for the development of teamwork. An alternate approach is to start, not from the practitioner and/or educational end but from the organisational and/or employer end of primary health care.

In the Netherlands, for example, where primary care is managed by the town or city, in many places all primary care practitioners are employees of the town or city. ${ }^{7}$ Thus, they are all part of the same organisation sharing a common view of primary healthcare provision and working to a shared plan. As Thomas argues, ${ }^{9}$ there is a need to combine the methods from adult learning with a whole-systems approach that looks at the primary healthcare team in the context of the health and social care system of which it is a part.

Meads and Ashcroft ${ }^{11}$ present a taxonomy of collaboration comprising eight factors, which they have identified from their extensive research and practice experience to be vital to an understanding of the complexity of the collaboration process. The eight factors are: goal, level, process, structure, power and influence, proximity, duration, and complexity. These factors illustrate the multiple aspects that combine to generate, achieve, or sabotage collaboration between members of teams and between teams.

Meads and Ashcroft ${ }^{11}$ argue that to be effective, teams need to examine and understand their individual and shared views of the eight elements. For example, teams need to be aware if the goals they are pursuing are 'functional', such as to deliver an enhanced immunisation service, or 'transformational', such as the development of ways in which members of the practice population might lead strategy development for the team. These two examples illustrate the next aspect: level of collaboration. The first example is at the 'operational' level, while the second is at the 'strategic' level. Collaboration might also be at the 'executive' level and, in some cases, to achieve collaboration collaborative relationships at all these levels will be needed. For example, provision of an urgent care service needs collaboration on the ground, at the executive and strategic levels. ${ }^{11}$

Different processes of exchange and cooperation and structures including networks, such as the primary care research networks, will be used in the process of teamwork and collaboration and team members need to have skills in collaborating in a range of different ways. Individuals and organisations will have different levels of power and influence within the relationships and team members need to be able to examine these. Collaboration will also be affected by space and time; collaborators may be in the same team or drawn from teams across the globe, and a collaboration may be for many years or short-term in duration, for example, a team set up to respond to an infectious disease outbreak. Finally, the collaborative relationship may involve only one other partner or multiple partners, as is frequently the case in primary care collaborations, such as those found in the care of the person with palliative care needs.

Health care, whether at the individual, community, or population level, is a combination of the interaction of a number of different elements: societal expectations; the system of organisation within the service; the knowledge, skills, and attitudes of the individuals providing a service; and the knowledge, skills, and attitudes of those receiving the service. ${ }^{12}$ In the case of the provision of palliative care services, at the societal level, demonstrated for example in health policy, there are expectations regarding the contribution of all members of the team; such as, the role of expert home-based services provided by a team of doctors, nurses, and others.

At the organisational level, such as between the primary healthcare and specialist palliative care teams, communication has to be open and with a clear process; for example, in the design of care pathways, monitoring service delivery, and being responsive to identified difficulties in service delivery. Within all organisations staff need to have the requisite levels of knowledge and skills to provide the service, but also attitudes to collaborative working that are positive and respectful. 
The knowledge, expectations, and requirements of those receiving the service will have an impact on the service provided and will relate back to the social and cultural norms of the wider society, local community, or other groups to which the individual and their family belong. Thus, the societal or macro-level expectations inter-relate with the organisation of primary care and palliative care services, and the delivery of the service to the community at the micro level. This awareness of the interrelatedness of the elements that make up a service demonstrates the need to address collaboration at the macro level.

Considerable effort has been expended over many years seeking to address the issue of collaboration from the micro level, for example, through teambuilding workshops and the use of shared and separate learning. ${ }^{1,10,13}$ These are important methods which continue to be relevant, for example in the implementation of the Gold Standards Framework, ${ }^{14}$ but there is a need to look beyond these methods to the wider arena. Development of teamworking and collaboration can be addressed at these different levels but, as discussed above, a whole-systems approach that provides support for collaboration at the macro or societal level and development of individuals at the micro or local level may be more effective in strengthening teamwork than individual interventions at either macro or micro level.

In this issue the two papers investigating teamwork in palliative care ${ }^{3,4}$ illustrate many of the features of a particular approach to developing interprofessional working, facilitated practice-based education, and the mixed outcomes found from this and other interventions to stimulate and support collaborative working. In a qualitative interview study Walshe et al conclude that judgemental attitudes held by primary care colleagues towards each other can have a negative impact on access to palliative care services. ${ }^{4}$ Similarly, Mahmood-Yousuf and colleagues conclude from their qualitative case study data that hierarchical relationships between, in particular, GPs and district nurses, impeded the provision of these services. ${ }^{3}$ These papers also illustrate the challenges of qualitative research and, at the same time, reinforce the centrality of the impact of the attitudes and expectations of the individual on teamworking.

Mahmood-Yousuf and colleagues interviewed a GP and district nurse from the same practice. The GP described a system of easy communication, with the district nurse contacting with him between patients to discuss care. The district nurse perceived this as a devaluation of her contribution and of the priority given to communication with her. $^{3}$ In contrast, a district nurse interviewed by Walshe et al valued this approach to communication, identifying this as illustrating the responsiveness of the GP. ${ }^{4}$ Communication depends on individuals, and individuals perceive and react to things in different ways:

\section{'Collaboration is, in part, a personal decision and is as much about who the individual is as about what they do. The professions can be the focus of collaboration, or a continuing source of difference. ${ }^{\prime 11}$}

Changing professional attitudes and expectations, it is argued, can be one means to change the individual. As illustrated earlier, ${ }^{3,4}$ implementation of the Gold Standards Framework was affected by the perceptions of the collaborative relationship between GPs and district nurses. While such differences in expectations may be addressed at the local team level, another approach is to take action at the professional level, for example through the initial preparation of nurses and doctors. One barrier to this approach has been the difference in the level of the first qualification of the doctor and the nurse. ${ }^{15}$ Although all nurses in Wales now study for a bachelor's degree, a minority of nurses in the other countries of the UK hold first degrees, the majority still qualifying with a diploma qualification. This is currently being considered through consultation on the initial preparation for nurses in which the option of a degreelevel profession has been has proposed..$^{16}$

Such a macro change may seem a long way from the delivery of palliative care in the home of an individual, but could have a profound impact on societal attitudes towards nurses and open up the opportunities for more joint learning and programmes at the undergraduate level, thus increasing understanding of (and the potential to modify) the behaviours of individuals in different professional groups, as demonstrated by the Common Learning programme at the Universities of Southampton and Portsmouth. ${ }^{17}$

Researchers concerned with the delivery of particular aspects of care, such as for those with diabetes, musculoskeletal problems, and renal disease, are increasingly turning their gaze towards primary care. As the authors of the two palliative care papers noted, ${ }^{3,4}$ their findings are related as much to the state of primary care as to the provision of this particular service:

\section{'It is likely that such judgemental} attitudes and practices affect many aspects of primary care, not just palliative care. ${ }^{\prime 4}$

In 1997 Kendrick and Hilton ${ }^{18}$ commented on the limiting effect inadequacies in primary care teamworking could have on the further development of primary care services, and more than 80 years ago Lord Dawson, in advocating the grouping of staff in health centres, acknowledged that there was a need to address the problems of teamworking in primary care. ${ }^{2}$ The continuing challenge is to combine the macro- and micro-level interventions to ensure that historic barriers to collaboration in primary care do not limit the relocation of care. Surely, the evidence and theoretical developments now provide us with enough information so that together we can affect change at societal, organisational, and individual levels to make a reality of collaborative working in primary care.

\section{Rosamund Bryar,}

Professor of Community and Primary Care Nursing, City University, London

\section{REFERENCES}

1. Pearson P, Spencer J (eds). Promoting teamwork in primary care. A research-based approach. London: Arnold, 1997.

2. Dawson B. Report on the future provision of medical and allied services. Cmd 693. London: HMSO, 1920.

3. Mahmood-Yousuf K, Munday D, King N, Dale J. Interprofessional relationships and communication in primary palliative care: the impact of the Gold Standards Framework. Br J Gen Pract 2008; 58(549): 256-263. 
4. Walshe C, Todd C, Caress A-L, Chew-Graham C. Judgements about fellow professionals and the management of patients receiving palliative care in primary care: a qualitative study. Br J Gen Pract 2008; 58(549): 264-272.

5. Craddock D, O'Halloran C, Borthwick A, McPhearson $\mathrm{K}$. Interprofessional education in health and social care: fashion or informed practice? Learn Health Soc Care 2006; 5(4): 220-242.

6 Thomas P, Graver L. The Liverpool intervention to promote teamwork in general practice: an action research approach. In: Pearson P, Spencer J (eds). Promoting teamwork in primary care. A research-based approach. London: Arnold, 1997: 174-191.

7. Bryar R. 'Since the centre started I am a different woman.' Report of a WHO fellowship visit to the Netherlands. Teamcare Valleys Completion Report. Cardiff: Teamcare Valleys, 1992.

8. West M, Poulton B. Primary health care teams: in a league of their own. In: Pearson, P, Spencer J (eds). Promoting teamwork in primary care. A research-based approach. London: Arnold, 1997: 12-26.

9. Thomas P. Integrating primary health care, leading managing, facilitating. Abingdon: Radcliffe Medical
Press, 2006.

10. Bryar R, Bytheway B. Changing primary health care. The Teamcare Valleys Experience. Oxford: Blackwell Science, 1996.

11. Meads G, Ashcroft J. The case for interprofessional collaboration in health and social care. Oxford: Blackwell Publishing, 2005.

12. Silverman D. The theory of organisations. London: Heinemann, 1970.

13. Freeth D, Hammick M, Barr H, Koppel I, Reeves S Effective interprofessional education: development delivery and evaluation. Oxford: Blackwell Science, 2005.

14. Addington-Hall J, Shipman C, Burt J, et al. Evaluation of the education and support programme for district and community nurses in the principles and practice of palliative care. London: King's College, 2006.

15. Pearson P, Steven A, Dickinson C. Learning together in practice. A final report on IPE for modernising health and social care. Newcastle: University of Newcastle, 2006.

16. Nursing and Midwifery Council. Review of preregistration nurse education. http://www.nmc-uk.org (accessed 6 Mar 2008).
17. Health Care Innovation Unit. Common learning. http://www.commonlearning.net/ (accessed $6 \mathrm{Ma}$ 2008)

18. Kendrick T, Hilton S. Primary care: opportunities and threats. Broader teamwork in primary care. BMJ 1997; 314(7081): 672-675.

DOI: 10.3399/bjgp08X279733

\section{ADDRESS FOR CORRESPONDENCE:}

\section{Rosamund Bryar}

Professor of Community and Primary

Care Nursing, Public Health, Primary Care and Food Policy Department,

City Community and Health Sciences,

City University, 20 Bartholomew Close,

London EC1A 7QN.

E-mail:R.M.Bryar@city.ac.uk

\section{The Tooke report: good news for general practice?}

During the 1960s - when it was still possible to enter general practice immediately after completion of the preregistration house officer year - the Royal College of General Practitioners (RCGP) sought to improve standards of care for patients by introducing vocational training for general practice.

Although the RCGP proposed a 5-year period of vocational training at that time, resource constraints within the NHS meant that only 3-year programmes could be developed, and with only 1 year in general practice itself.

Initially voluntary, there was no requirement to undertake any training until 1978 when primary legislation was introduced making it mandatory to complete 12 months in general practice. Subsequent changes to the legislation in 1983 required completion of 3 years' training to become a principal and in 1990 required completion of training to work in any capacity within general practice. Although the majority of trainees took the MRCGP examination, there was no requirement to demonstrate satisfactory completion of training until 1996 when summative assessment became mandatory.

The changes brought about by the Postgraduate Medical Education and Training Board (PMETB) gave us the opportunity to develop specialty training for general practice, ensuring that doctors have the competences necessary to provide high standards of medical care for patients.

The PMETB set explicit standards for both the training curriculum and the assessment of completion of training that needed to be met by all medical specialties including general practice. The curriculum for general practice ${ }^{1}$ was given unconditional approval by PMETB. Although the curriculum is competencerather than time-based, the PMETB approval panel rightly questioned the RCGP closely on the challenges of completing training in such a complex discipline in only 3 years.

Although general practice is the most widely challenging field of medical practice, it has the shortest period of specialty training. The nature of practice and the complexity of clinical care delivered by GPs have changed dramatically since the inception of GP training schemes - yet the duration of training has not increased to take account of this.

This is reflected in various documents from all four Departments of Health and given particular emphasis in Modernising Medical Careers: The Next Steps ${ }^{2}$ (MMC). This key document highlights that: 'The advent of Modernising Medical Careers offers the opportunity to develop a new and better approach to GP training ... which is a significant improvement over existing arrangements ... GP training will increasingly be based in and from general practice'.

This was further highlighted in Sir John Tooke's review ${ }^{3}$ which concluded that: '... although a deeply damaging episode for British medicine, from this experience must come a recommitment to optimal standards of postgraduate medical education and training.' One of the key recommendations made by Tooke is that ' ... the length of training in general practice should be extended to 5 years'. This recommendation has attracted widespread support from across the profession, not just from general practice. 